\title{
Article \\ Retrofitting Sea Cucumber Nursery Tanks to Recirculating Aquaculture Systems for Highly Intensive Litopenaeus vannamei Aquaculture
}

\author{
Yishuai Du ${ }^{1,2}$, Jianping Xu ${ }^{1,2}$, Li Zhou ${ }^{1,2}$, Fudi Chen ${ }^{1,2}$, Tianlong Qiu ${ }^{1,2}$ and Jianming Sun ${ }^{1,2, *}$ \\ 1 CAS Key Laboratory of Experimental Marine Biology, Institute of Oceanology, Chinese Academy of Sciences, \\ 7 Nanhai RD, Qingdao 266071, China; duyishuai@qdio.ac.cn (Y.D.); 18354203286@163.com (J.X.); \\ zhouli@qdio.ac.cn (L.Z.); fordie@126.com (F.C.); oceanman@163.com (T.Q.) \\ 2 Center for Ocean Mega-Science, Chinese Academy of Sciences, 7 Nanhai RD, Qingdao 266071, China \\ * Correspondence: jianming_sun@outlook.com; Tel.: +86-0532-82863893
}

Citation: Du, Y.; Xu, J.; Zhou, L.; Chen, F.; Qiu, T.; Sun, J. Retrofitting Sea Cucumber Nursery Tanks to Recirculating Aquaculture Systems for Highly Intensive Litopenaeus vannamei Aquaculture. Appl. Sci. 2021, 11, 9478. https://doi.org/10.3390/ app11209478

Academic Editors: María

Dolores Gómez-López, Jesús

Montero Martínez and

Adriana Correa

Received: 25 July 2021

Accepted: 8 October 2021

Published: 12 October 2021

Publisher's Note: MDPI stays neutral with regard to jurisdictional claims in published maps and institutional affiliations.

Copyright: (C) 2021 by the authors Licensee MDPI, Basel, Switzerland. This article is an open access article distributed under the terms and conditions of the Creative Commons Attribution (CC BY) license (https:/ / creativecommons.org/licenses/by/ $4.0 /$ )

\begin{abstract}
Designing good recirculating aquaculture systems (RASs) is challenging in shrimp aquaculture. In this study, two sets of RASs were constructed using sea cucumber nursery tanks for rearing Litopenaeus vannamei. Recirculating aquaculture was supported by key technologies such as sewage collection and aeration systems adapted to the rectangular tanks and technologies for the removal of sewage, shrimp shells, and dead individuals. Six-hundred and eighty-five thousand juveniles were selected for rearing in the newly constructed RASs, where the average stocking density was 1013 shrimp $/ \mathrm{m}^{3}$. During the recirculating aquaculture period of 53 days, the water temperature of the tanks was $24-31{ }^{\circ} \mathrm{C}$, the salinity was $25-32 \%$, the $\mathrm{pH}$ was $6.4-8.2$, the DO was $\geq 4.9 \mathrm{mg} / \mathrm{L}$, the concentration of total ammonia nitrogen (TAN) was maintained between 0.17 and $4.9 \mathrm{mg} / \mathrm{L}$, the concentration of nitrite nitrogen $\left(\mathrm{NO}_{2}-\mathrm{N}\right)$ was between 0.12 and $4.7 \mathrm{mg} / \mathrm{L}$, and the total number of Vibrio bacteria remained between 330 and $9700 \mathrm{cfu} / \mathrm{mL}$. At the end of the experiment, the final average weight of individual shrimp was $13.43 \mathrm{~g}$, and the average yield reached $12.92 \mathrm{~kg} / \mathrm{m}^{3}$. The great improvement in growth performance marks a breakthrough in RAS technology of shrimp, and it supports the use of an innovative methodology for the retrofitting and utilization of idle sea cucumber nursery tanks.
\end{abstract}

Keywords: Litopenaeus vannamei; recirculating aquaculture system; intensive shrimp culture; industrial aquaculture; retrofit

\section{Introduction}

In recent years, a large number of maricultured sea cucumbers died due to high temperatures experienced in northern China during the summer, causing a significant decrease in the cultured production of these species. In 2018, the production of maricultured sea cucumbers in China was 174,340 tons, which was 20.72\% lower than that in $2017(219,907$ tons) [1]. The death of a large number of sea cucumbers brought huge economic losses to the farming industry, determining its decline. At present, in Chinese coastal areas, especially in Liaodong and Shandong Peninsulas, many rectangular nursery tanks, normally used as sea cucumber nurseries, are idle, and this represents a significant waste of resources. However, while the sea cucumber farming industry experiences a dramatic decline, the whiteleg shrimp (Litopenaeus vannamei) farming industry is currently expanding in China. In 2018 and 2019, the production of maricultured Litopenaeus vannamei was 1,117,534 and 1,144,370 tons, respectively, and the production of freshwater cultured Litopenaeus vannamei was 642,807 and 671,180 tons, respectively [1,2]. Nevertheless, China still needs to import nearly one million tons of Litopenaeus vannamei every year from abroad to meet the domestic demand. Such a high demand for whiteleg shrimp offers opportunities to further develop the farming of this species. Using the idle sea cucumber nursery tanks for this purpose has 
been proposed. However, using rectangular sea cucumber nursery tanks in the traditional factory-based water flow shrimp culture mode could not meet the requirements under the pressure of national environmental protection policies. Recirculating aquaculture system (RAS) technology represents the most advanced development in aquaculture, and it will define the future of this sector [3]. As such, it was proposed as a solution to the problem of successfully repurposing the sea cucumber tanks: these nursery tanks were retrofitted to RASs for Litopenaeus vannamei farming, ultimately re-establishing a rational use of resources and bringing significant economic benefits.

In the 1990s, several experiments were carried out in the United States using recirculating raceway systems to rear Litopenaeus vannamei [4]. In the past 30 years, scientists have continuously explored the recirculating aquaculture modes for rearing Litopenaeus vannamei. These recirculating aquaculture technologies include raceway RAS [5], high place pond RAS [6], fully enclosed land-based RAS [7-9], constructed wetland RAS [10], and small RAS experimental facilities [11-14]. However, few reports on farms containing a water volume exceeding $100 \mathrm{~m}^{3}$ and an average biomass yield above $6 \mathrm{~kg} / \mathrm{m}^{3}$ have been published so far for this species. Recirculating aquaculture has the advantage of allowing high stocking densities and has been recognized as the way forward in terms of future development of aquaculture technology. However, RAS technology is not yet sufficiently applicable to the large-scale, high-density, and high-yield farming of Litopenaeus vannamei. Therefore, for this particular species, RAS aquaculture needs further experimentation and upgrading.

The traditional shrimp farming industry in China is restricted by factors such as climate change, shrimp larval quality, and disease outbreaks. Shrimp production largely depends on weather conditions. There is no planning or stability in this type of farming, and it is not possible to achieve stable improvements in shrimp production [1,2]. At the same time, the discharge of aquaculture wastewater, which does not meet the industrial development requirements in China, causes tremendous pressure on the environment. Therefore, the shrimp farming industry in China has come to a crossroads, and a reform is urgently needed. Recirculating aquaculture systems use industrialized means to artificially control the water environment in culture tanks and create better conditions for shrimp survival and growth [15]. RASs have the advantages of occupying limited land areas, producing high yields, and having generally high profitability. This technology is more environmentally sustainable and is able to control the entire process of aquaculture production; therefore, it is more suitable to the shrimp-farming industry in China.

In our previous research, we addressed the problems of sewage collection and aeration in rectangular sea cucumber nursery tanks [16]. Drawing on those findings, a sea cucumber nursery facility was here retrofitted to two fully enclosed land-based recirculating aquaculture systems to be used for highly intensive aquaculture of Litopenaeus vannamei. Subsequently, water treatment and culture performance during the aquaculture period were analyzed and evaluated. The purpose of this research was to seek a breakthrough in the recirculating aquaculture technology for Litopenaeus vannamei culture and to explore new methods to retrofit and utilize idle sea cucumber nursery tanks.

\section{Materials and Methods}

\subsection{Elements of the Recirculating Aquaculture System (RAS)}

Two sets of RASs to be used for Litopenaeus vannamei culture were constructed in Dalian, Liaoning Province, China. The structure and elements involved in the process are shown in Figure 1 and Figure S1. Each RAS consisted of culture tanks, a reservoir, circulation pumps, a micro filter, biofilters, a foam fractionator, an ozone generator, ultraviolet disinfection equipment, and a central control system. Each system contained 13 rectangular cement culture tanks, and each tank was $6.3 \mathrm{~m}$ long, $3.2 \mathrm{~m}$ wide, and $1.6 \mathrm{~m}$ high. The water depth was maintained at $1.3 \mathrm{~m}$. The total water volume for each RAS was $338 \mathrm{~m}^{3}$. The effective volume of the reservoir was $40 \mathrm{~m}^{3}$. The flow of the recirculation pump was $200 \mathrm{~m}^{3} / \mathrm{h}$, which could be adjusted using a frequency converter. The microfilter consisted of 260 mesh nylon screens that were able to filter out large particles such as 
uneaten feed and feces in the water body and was equipped with an automatic backwash device controlled by the water level. The biofilter consisted of six cylindrical moving bed biofilm reactors (MBBR), which measured $1.5 \mathrm{~m}$ in diameter and $2.6 \mathrm{~m}$ in height and which were combined in parallel. These were mainly used to remove ammonia nitrogen, nitrite, and nitrate from the water. The total volume of the biofilter was $27.6 \mathrm{~m}^{3}$, and the available volume was $24 \mathrm{~m}^{3}$. The biofilter was filled with polyethylene (PE) biomedia rings that measured $25 \times 4 \mathrm{~mm}$; their specific surface area was $1300 \mathrm{~m}^{2} / \mathrm{m}^{3}$, and their specific gravity was $0.97-0.99 \mathrm{~g} / \mathrm{cm}$. The flow rate of the foam fractionator, which was connected to the ozone generator, was $200 \mathrm{~m}^{3} / \mathrm{h}$. Dissolved and suspended materials in the water were removed through the foam fractionator and ozone oxidation reactions, and simultaneously sterilization, disinfection, and aeration were carried out. Eight UV disinfection lamps with a total power of $2.6 \mathrm{~kW}$ were set up. The liquid oxygen Dewar tank was connected to the water outlet pipe of the foam fractionator through an oxygen pipe, and a gas flow meter was used to control the flow of pure oxygen. The central control system was used to maintain the parameters for the optimal functioning of the equipment, including the micro filter, circulating pumps, and foam fractionator. Variations of the recirculating pump frequency, liquid oxygen flow rate and ozone flow rate over time during the RAS culture period are shown in Table 1.

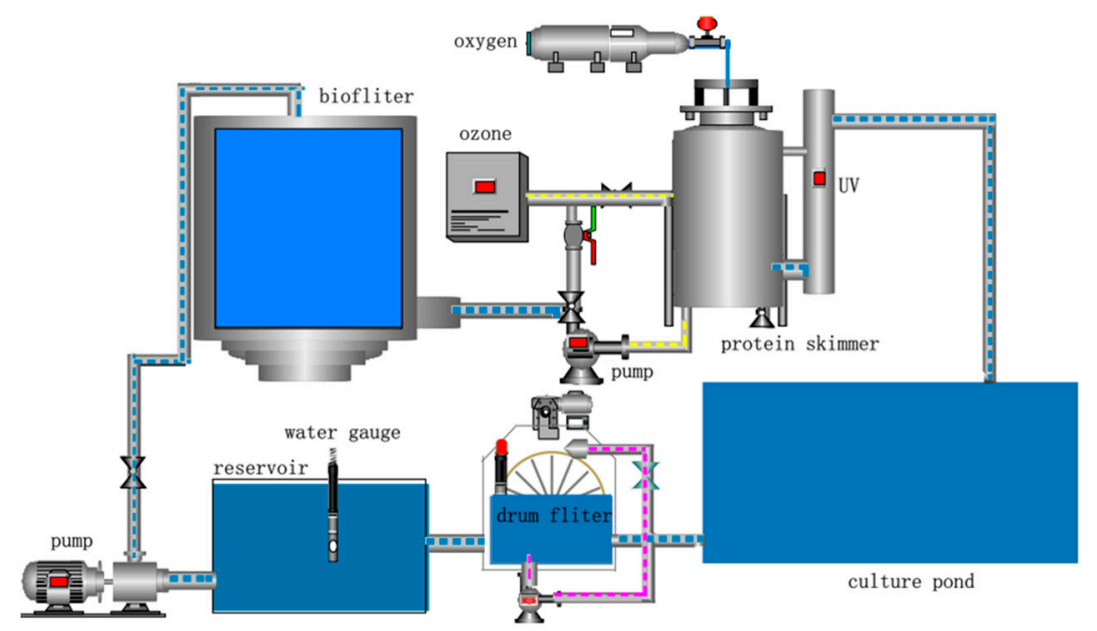

Figure 1. Flow chart depicting the recirculating aquaculture system.

Table 1. Variations in the recirculating pump frequency, the liquid oxygen flow rate, and the ozone flow rate over time during the RAS culture period.

\begin{tabular}{|c|c|c|c|c|c|c|c|}
\hline \multicolumn{2}{|c|}{ Recirculating Pump } & \multicolumn{3}{|c|}{ Liquid Oxygen } & \multicolumn{3}{|c|}{ Ozone } \\
\hline $\begin{array}{l}\text { Time } \\
\text { (d) }\end{array}$ & $\begin{array}{l}\text { Recirculating Pump } \\
\text { Frequency } \\
(\mathbf{H z})\end{array}$ & $\begin{array}{l}\text { Time } \\
\text { (d) }\end{array}$ & $\begin{array}{l}\text { Flow Rate } \\
\qquad\left(\mathrm{m}^{3} / \mathrm{h}\right)\end{array}$ & $\begin{array}{l}\text { Hours per Day } \\
\text { (h/d) }\end{array}$ & $\begin{array}{l}\text { Time } \\
\text { (d) }\end{array}$ & $\begin{array}{l}\text { Flow Rate } \\
\qquad\left(\mathrm{m}^{3} / \mathrm{h}\right)\end{array}$ & $\begin{array}{l}\text { Hours per Day } \\
\text { (h/d) }\end{array}$ \\
\hline $0-20$ & $26-30$ & $0-20$ & 0 & 0 & 0-15 & 0.2 & 4 \\
\hline $21-30$ & $30-40$ & $21-40$ & 0.2 & $24 \mathrm{~h}$ & $16-32$ & 0.2 & 6 \\
\hline $31-53$ & $40-50$ & $41-53$ & 0.4 & $24 \mathrm{~h}$ & $33-53$ & 0.4 & 10 \\
\hline
\end{tabular}

Note: if water turbidity was high, the recirculation flow was increased by adjusting the frequency of the recirculating pump to $50 \mathrm{~Hz}$ for a specific period of time.

\subsection{Key Technologies of the RAS Applied to Litopenaeus Vannamei Culture}

\subsubsection{Sewage Collection and Aeration in Rectangular Aquaculture Tanks}

In order to maximize the use of the aquaculture area, sea cucumber nursery tanks have a rectangular shape, and aerated stones are generally used to ensure proper aeration. In order to meet the sewage collection requirements in the RAS, we improved aeration and oxygenation methods. Fine-pore aeration tubes were arranged at the four corners of the 
rectangular aquaculture tanks, and they were used to both gather accumulated sewage and to aerate the water. Details of the construction and functioning of sewage collection and aeration methods have been published [16]: the fine-pore aeration tubes were made of polymer materials, with an outer diameter of $16 \mathrm{~mm}$, an inner diameter of $12 \mathrm{~mm}, 700-1200$ holes per meter, and a bubble diameter of $0.5-2.0 \mathrm{~mm}$. These tubes, each measuring $2.5 \mathrm{~m}$ in length, were fixed at the four corners of the tank bottom. The total length of the fine-pore aeration tubes in each culture tank was $10 \mathrm{~m}$. The tubes were connected to the Roots blower through the mesh hose and PVC pipe, and the average air intake of each culture tank was maintained at 250-300 L/min. After the sewage was gathered at the center of each tank by the aeration taking place at the four corners, it was removed through a sewage collection pipe installed at the center of the tank bottom (Figure 2).

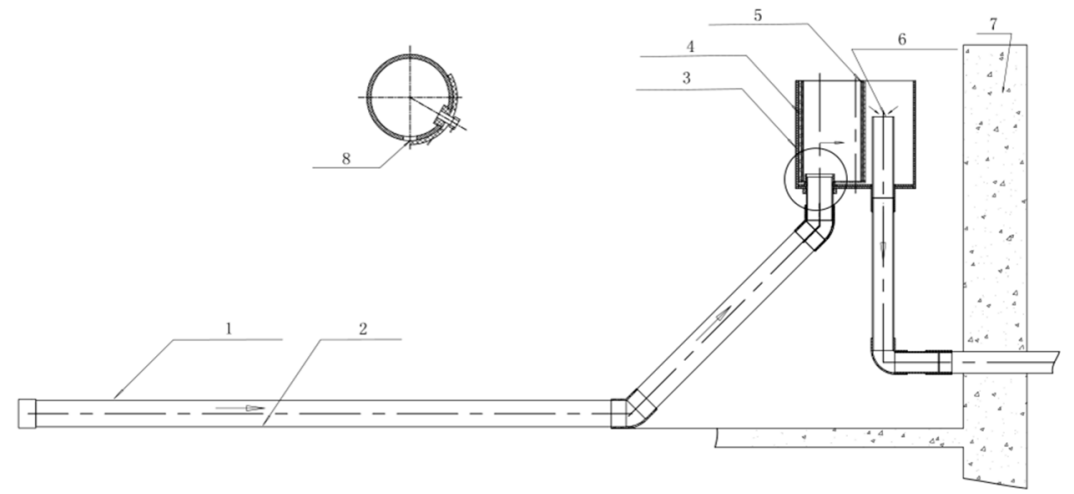

Figure 2. Device for the removal of shrimp shells, dead individuals, and sewage. (1) Sewage collection pipe; (2) long strip sewage collection opening; (3) backwater drainage tank; (4) live shrimp anti-escape frame; (5) anti-escape net; (6) fixed water level pipe; (7) tank wall; (8) gap in sewage collection opening with adjustable size.

\subsubsection{Shrimp Shell, Dead Shrimp, and Sewage Removal Technology}

A device for the removal of shrimp shells, dead individuals, and sewage was designed and put in place (CN201811548991.1). An adjustable opening was located at the bottom of the sewage collection pipe so that the sewage collection flow could be controlled. A backwater drainage tank was placed on the tank surface, and a live shrimp anti-escape frame with anti-escape nets inside was installed. Shrimp shells, dead individuals, and small live shrimp flowing in from the sewage collection pipe at the bottom of the tanks were retained in the anti-escape nets, while the sewage was directed into the backwater pipe through the anti-escape nets (Figure 2). It is more difficult for RAS of shrimp than fish, and the successful application of this device in this study is the key to the success of shrimp culture in RAS.

\subsubsection{Variable Flow Recirculating Aquaculture Technology}

The flow of the recirculating pump was controlled through a frequency converter. Different recirculating flow rates were adopted in different stages of the culture and in different levels of turbidity present in the water body [17]. Variable-flow recirculating technology removed particulate organic matter in the tanks promptly, reducing the production of ammonia nitrogen and nitrite at the source, and thus ensuring the water quality of the system while saving a lot of energy. The main changes in the recirculating pump frequency during the culture period are shown in Table 1.

\subsection{Litopenaeus vannamei Culture Process and System Management} 2.3.1. Nursery Management and Culture in the RAS

On 18 April 2018, 1.2 million commercial Litopenaeus vannamei post-larvae (PL 5, average weight $0.0018 \mathrm{~g}, n=300$ ) were purchased and placed in four nursery tanks at a stocking density of 10,000 to $11,000 \mathrm{PL} / \mathrm{m}^{3}$. After 39 days at the nursery tanks, they 
were moved into the RAS. During the nursery period, the aquaculture water temperature was $26-28^{\circ} \mathrm{C}$, the salinity was $25-30 \%$, and the $\mathrm{pH}$ was $7.5-8.5$. In the early stage of the nursery period, the water quality was mainly adjusted through algae propagation, while in the later stage it was controlled through microecological agents and water exchange.

On 27 May 2018, after the nursery period was completed, 685,000 juvenile Litopenaeus vannamei (average weight $0.4 \mathrm{~g}$ ) individuals were selected and moved into 26 culture tanks in two RAS sets, which consisted of 13 tanks each. The average stocking density was about $1013 \mathrm{shrimp} / \mathrm{m}^{3}$. In the first RAS (RAS1), the stocking density was $1150 \mathrm{shrimp} / \mathrm{m}^{3}$ in four culture tanks and 960 shrimp $/ \mathrm{m}^{3}$ in the other nine culture tanks. In the second RAS (RAS2), the stocking density was 1150 shrimp $/ \mathrm{m}^{3}$ in three culture tanks and $960 \mathrm{shrimp} / \mathrm{m}^{3}$ in the other ten.

\subsubsection{Growth Indexes}

The average weight of shrimp in the two RASs was measured every four to six days. Between 200 and 300 shrimp were randomly sampled each time from six culture tanks with a density of $960 / \mathrm{m}^{3}$ and from two tanks with a density of $1150 / \mathrm{m}^{3}$. The total weight was measured after the water was drained. Once the number of individuals sampled was counted, the shrimp were put back to the tanks, and their average weight was calculated. Dead individuals were collected from the live shrimp anti-escape frame every day and they were taken into account in shrimp stock assessment calculations. Shrimp biomass in the RAS was calculated based on the shrimp average weight and the stocking density. The amount of feed was then calculated based on biomass numbers.

\subsubsection{Feeding Management}

Shrimp were fed six times a day at 7:00, 10:00, 13:00, 16:00, 19:00, and 22:00. In the early stage of culture (1-20 days after entering the RAS), shrimp were fed four times a day with the No. 1 compound diet and twice a day with chilled copepods at $8-10 \%$ of the shrimp biomass. In the second phase (21-42 days), shrimp were fed six times a day with the No. 2 compound diet together with the main feed and an appropriate number of chilled copepods as supplements at $5-8 \%$ of the shrimp biomass. In the late stage of culture (between 43 days and harvest), feeding occurred six times a day but only with the No. 2 compound diet at $3-5 \%$ of the total shrimp biomass. The feed had to be eaten within $1 \mathrm{~h}$ or within $1.5 \mathrm{~h}$. Whether the amount of feed was sufficient was determined through direct observation of uneaten feed accumulating in the backwater drainage tank, as well as through the observation of molting, so feed was added or subtracted accordingly. During the molting period or when water quality parameters were poor, it was considered appropriate to reduce the amount of feed or even stop feeding altogether. The mass of chilled copepods was converted into dry weight at a conversion rate of $15 \%$, and the daily feeding amount was calculated by adding the dry weight of chilled copepods to the amount of compound diet.

\subsubsection{Water Quality Management}

In this study, exogenous seawater or underground well water were pumped into the disinfection tank in the culture greenhouse. After disinfection, the water was heated through solar exposure until it reached an appropriate temperature, and it then entered the RASs as source water for the culture. The water used in the initial period of recirculating aquaculture was all exogenous seawater (salinity about 31\%o). Underground well water (salinity about 20\%o) was gradually added during the middle stage, until the salinity of the aquaculture water dropped to about $25 \%$, and then the daily addition of exogenous seawater gradually brought the salinity up to approximately $29 \%$. In order to maintain DO above $5.0 \mathrm{mg} / \mathrm{L}$, liquid oxygen $\left(0.2 \mathrm{~m}^{3} / \mathrm{h}, 24 \mathrm{~h} / \mathrm{d}\right)$ was added from the 20th day of RAS culture onwards, and the amount $\left(0.4 \mathrm{~m}^{3} / \mathrm{h}, 24 \mathrm{~h} / \mathrm{d}\right)$ was further increased from the 30th day onwards. Temperature (T), dissolved oxygen (DO), salinity, and $\mathrm{pH}$ in three culture tanks randomly selected from each RAS system (RAS1 and RAS2) were measured 
using YSI PROplus at 8:00, 14:00, and 20:00 every day. The average values represented the water quality index of each RAS. During the first ten days of RAS culture, the contents of total ammonia nitrogen (TAN) and nitrite nitrogen $\left(\mathrm{NO}_{2}-\mathrm{N}\right)$ and the total number of Vibrio present in two RASs were determined every five days. Between days 11 and 20, they were determined every two days, and between days 21 and 53, they were measured every day. The total ammonia nitrogen (TAN) and nitrite nitrogen $\left(\mathrm{NO}_{2}-\mathrm{N}\right)$ were measured using a YSI 9500 photometer: TAN was determined in the Phot 4 program and nitrite nitrogen $\left(\mathrm{NO}_{2}-\mathrm{N}\right)$ in the Phot 24 program. The total number of Vibrio was calculated through plate culture on TCBS. The daily addition of liquid oxygen and ozone in the two RASs for the culture of Litopenaeus vannamei is shown in Table 1 . The UV lamp was constantly on during the culture period. The initial biological media filling rate in the MBBR was $58.3 \%$, which contained $10 \%$ of mature media (the mature media were sourced from a RAS for grouper culture with a density of $80 \mathrm{~kg} / \mathrm{m}^{3}$ ). On the 41 st day of RAS culture, $1 \mathrm{~m}^{3}$ of new media was added to each MBBR, and the filling rate of biological media reached $62.5 \%$.

\section{Results}

\subsection{Shrimp Growth}

After 1.2 million post-larval shrimp (PL 5) were cultured in nursery tanks for 39 days, a total of 692,000 post-larval shrimp survived (survival rate, 57.5\%). A total of 685,000 post-larval shrimp were selected and transferred to the RAS. After 53 days of culture, 650,400 shrimp survived (survival rate, 94.95\%). During the 53-day RAS culture period, the average weight of the shrimp increased from $0.4 \mathrm{~g}$ to $13.43 \mathrm{~g}$, and the total biomass increased from $274 \mathrm{~kg}$ to $8735 \mathrm{~kg}$, so the total weight gain was $8461 \mathrm{~kg}$ (Figure 3). After 92 days of culture, the yield reached $12.92 \mathrm{~kg} / \mathrm{m}^{3}$. The dry weight of daily feed in the two RASs is shown in Figure 4. The amount of feed gradually increased to a maximum of 270 $\mathrm{kg}$. At a later stage of the culture, the feed amount was reduced in order to maintain water quality parameters. During the RAS culture period, a total of $7912 \mathrm{~kg}$ of dry weight feed including $2405 \mathrm{~kg}$ of copepods (which were converted to a dry weight of $361 \mathrm{~kg}$ ) and 7551 $\mathrm{kg}$ of commercial feed were consumed.
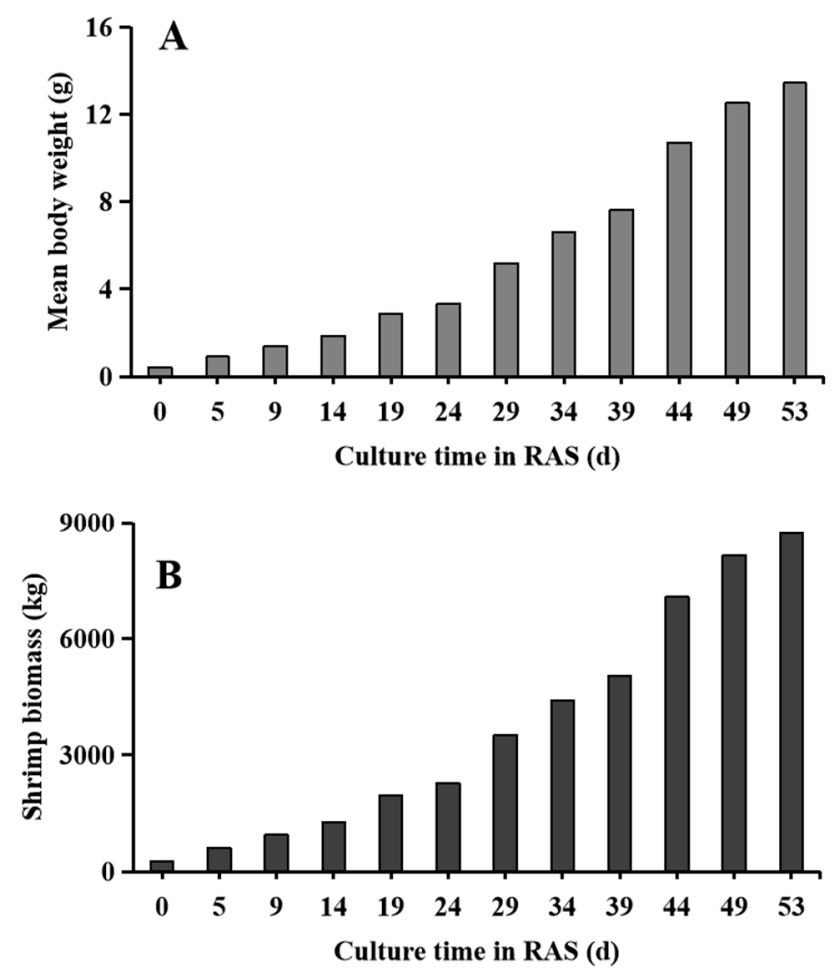

Figure 3. Changes in average body weight (A) and biomass (B) of whiteleg shrimp, Litopenaeus vannamei, during the recirculating aquaculture period. 


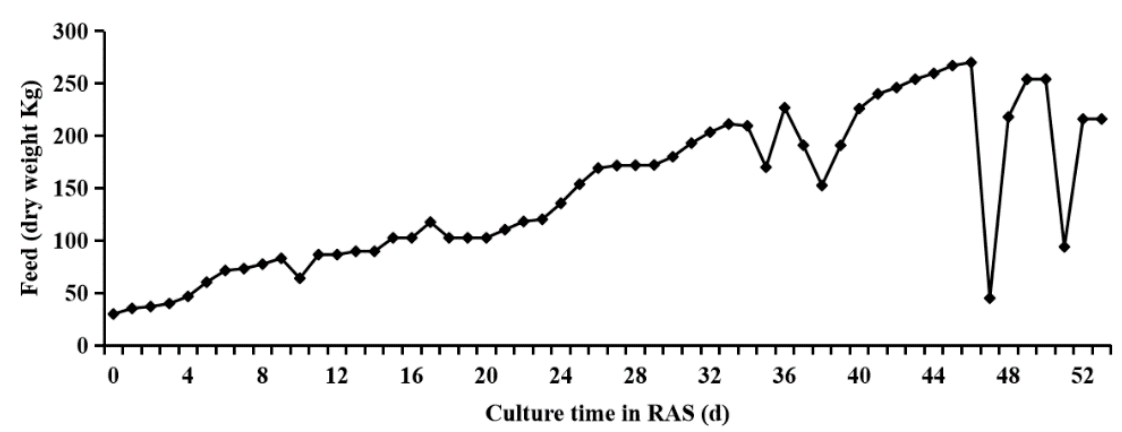

Figure 4. Changes in daily feed amount during the recirculating aquaculture period.

\subsection{Changes in Water Quality Parameters during RAS Culture}

During the entire RAS culture period, water temperature increased gradually from 24 to $31^{\circ} \mathrm{C}$ (Figure 5A), and salinity fluctuated between $25 \%$ and $32 \%$ (Figure 5B). Dissolved oxygen (DO) declined gradually from $7.0 \mathrm{mg} / \mathrm{L}$ to $5.0 \mathrm{mg} / \mathrm{L}$ in the early stage (0-20 days). After 20 days, liquid oxygen was added, and the DO level was thus maintained above $5.0 \mathrm{mg} / \mathrm{L}$ (Figure 6A). The $\mathrm{pH}$ of the culture water gradually decreased from an initial value of 8.2 to about 6.4 (Figure $6 \mathrm{~B}$ ).

\subsection{Water Purification Performance of Biofilm and Pathogen Control}

During the entire RAS culture period, the total number of Vibrio was maintained at $300-10000 \mathrm{cfu} / \mathrm{mL}$ (Figure 7A). It gradually increased in the early stage, fluctuating between 4000 and 10,000 $\mathrm{cfu} / \mathrm{mL}$, but it was controlled by the combined use of ultraviolet sterilization and ozone in later stages of culture. Total ammonia nitrogen concentrations (TAN) of both RASs gradually increased during the culture period (Figure 7B). During the first 30 days, TAN was stable at $2.0 \mathrm{mg} / \mathrm{L}$. With the increase in feed amount in the late stage of culture, ammonia nitrogen accumulated, and TAN reached the highest level at $4.8 \mathrm{mg} / \mathrm{L}$. The TAN content was controlled by reducing the feed amount in the late stage. Nitrite nitrogen $\left(\mathrm{NO}_{2}-\mathrm{N}\right)$ concentrations in the two RASs also gradually increased (Figure $7 \mathrm{C}$ ). The value was maintained within $1 \mathrm{mg} / \mathrm{L}$ during the first 38 days of culture, while nitrite accumulated and reached $4.7 \mathrm{mg} / \mathrm{L}$ in later stages.
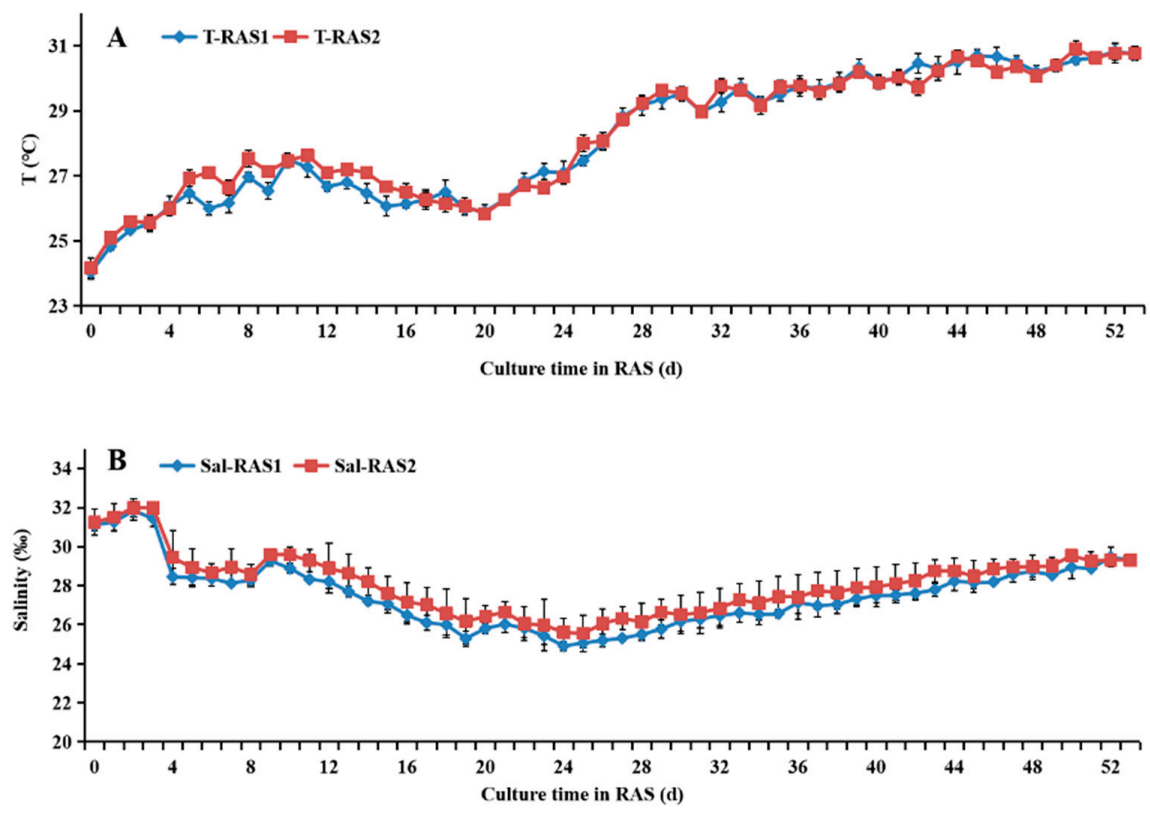

Figure 5. Changes in temperature (A) and salinity (B) in the culture tanks during the recirculating aquaculture period (means $\pm \mathrm{SE}, n=3$ ). 

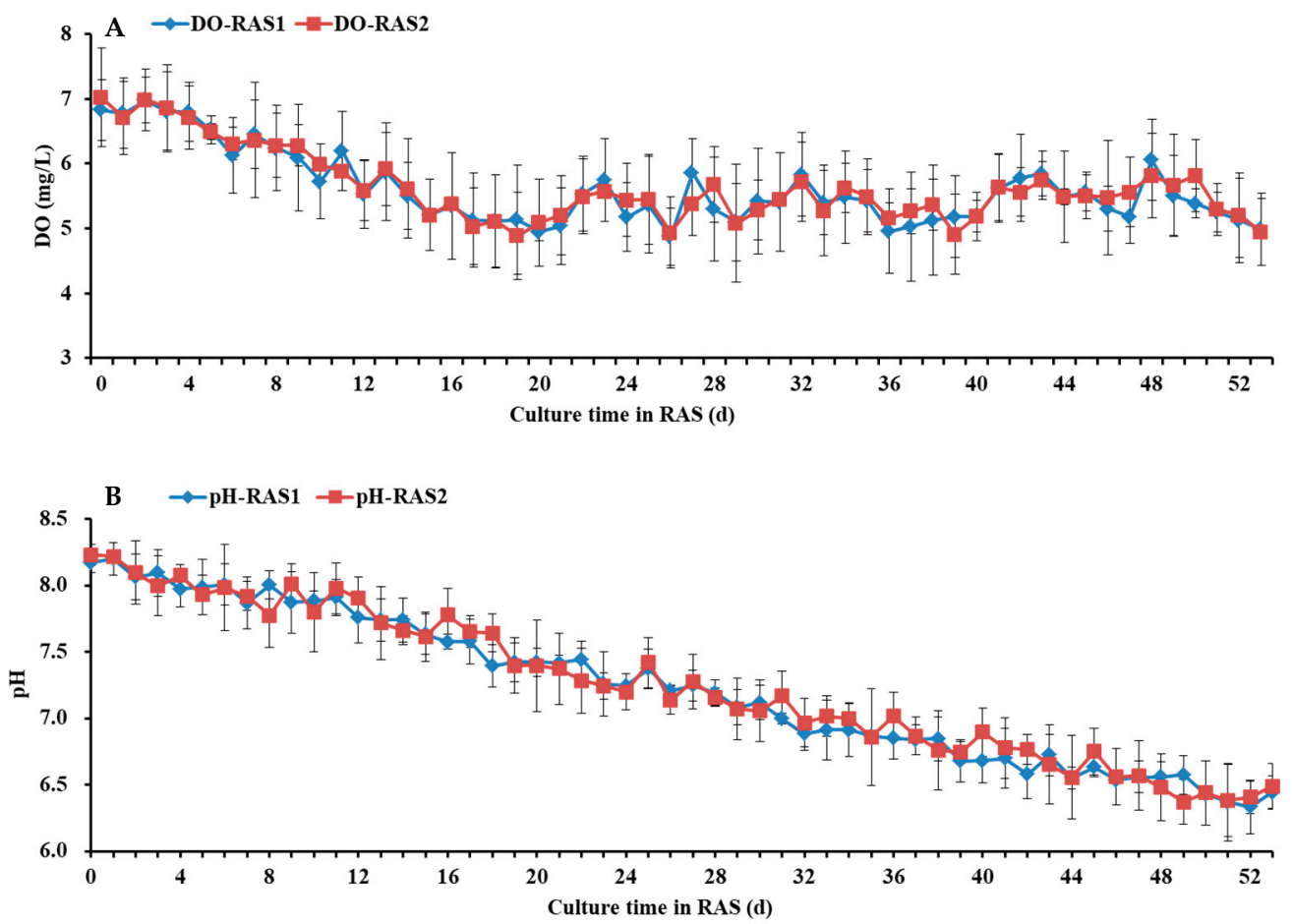

Figure 6. Changes in $\mathrm{pH}(\mathrm{A})$ and $\mathrm{DO}(\mathbf{B})$ in the culture tanks during the recirculating aquaculture period (means $\pm \mathrm{SE}$, $n=3)$.
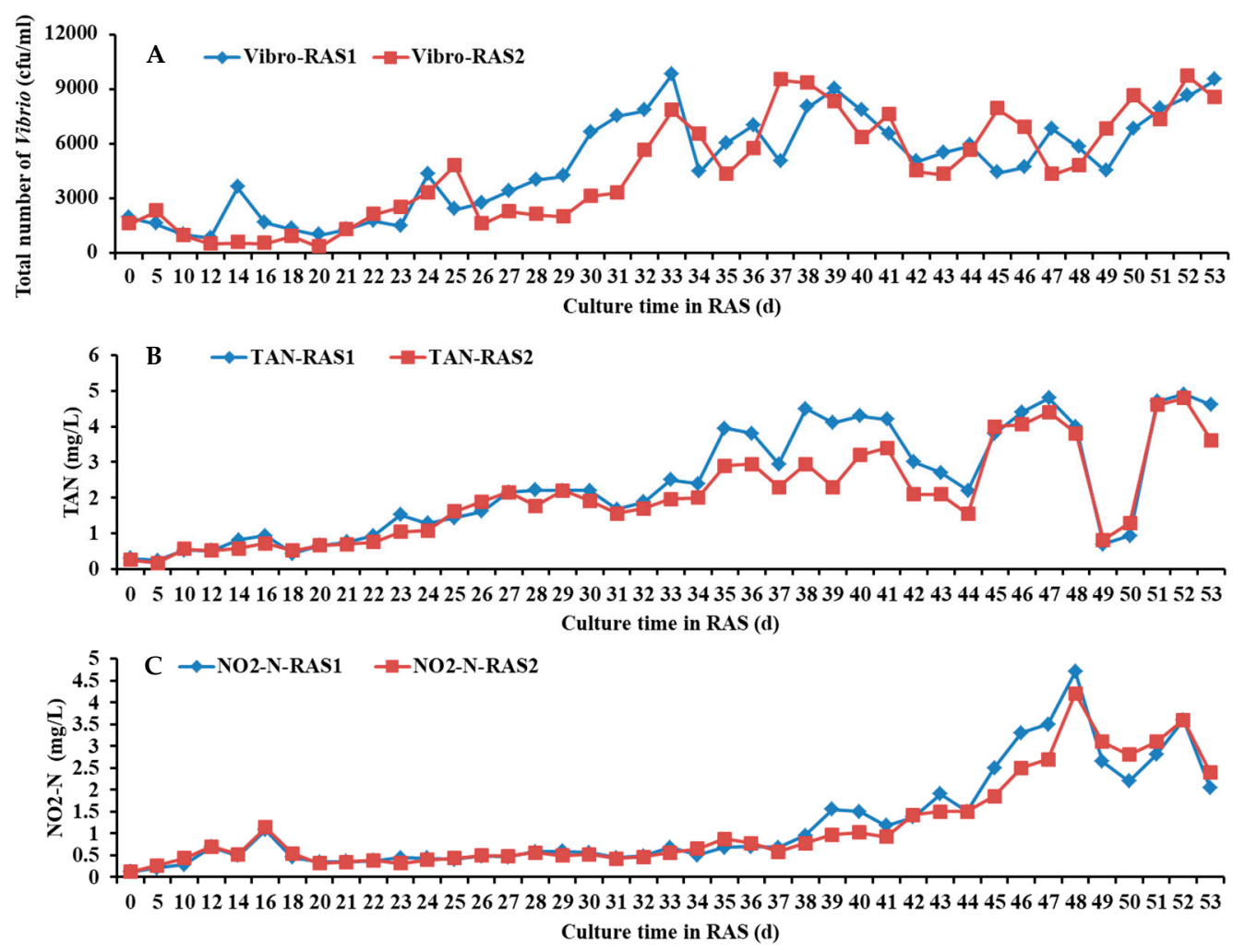

Figure 7. Changes in the total number of Vibrio (A), total ammonia nitrogen (TAN) (B), and nitrite nitrogen $\left(\mathrm{NO}_{2}-\mathrm{N}\right)(\mathrm{C})$ in the culture tanks during the recirculating aquaculture period. 


\section{Discussion}

In recirculating aquaculture systems, gathering the sewage in the water body to a specific area is one of the many essential steps [16]. Removing shrimp shells, dead individuals, and sewage in time are challenging tasks but essential to ensure the success of this particular aquaculture process. In order to prevent shrimp from escaping, the backwater outlet is designed to allow the opening of gaps [18], and anti-escape nets and similar tools are added [19]. However, these often lead to the clogging of outlets. A large amount of shells may be present in the water after molting, and they can block the backwater outlet, hindering water recirculation. In this study, a device to remove shrimp shells, dead individuals, and sewage was designed (CN201811548991.1) and put in place in order to avoid clogging. The backwater sewage collection pipe of the device was located at the bottom of the rectangular tanks that were once used as sea cucumber nursery tanks. The opening of the sewage collection pipe was designed as a long strip. The width of the opening could be adjusted according to shrimp size, so that only shrimp shells, dead individuals, and sewage could pass through. A backwater drainage tank equipped with a live-shrimp anti-escape frame and anti-escape nets with adjustable mesh size was installed in the upper layer of the culture tanks. The installation of anti-escape nets not only solved the problem of potential blockage of the backwater passage, but it also allowed the retention of live shrimp that entered the net through the sewage collection pipe. These were returned to the culture tanks regularly. The use of the device for the removal of shrimp shells, dead individuals, and sewage ensured the smooth functioning of water recirculation in the RAS. The adoption of a variable flow, regulated by the recirculating pump with adjustable frequency, contributed to a more energy-saving and efficient RAS.

After 53 days of recirculating aquaculture (the total culture time was 92 days including the nursery period), the final culture yield of whiteleg shrimp, Litopenaeus vannamei, reached $12.92 \mathrm{~kg} / \mathrm{m}^{3}$, which was a considerably larger amount compared to yields obtained using other shrimp culture technologies. The culture density of Litopenaeus vannamei at the time of harvest in traditional pond cultures is generally about $1-2 \mathrm{~kg} / \mathrm{m}^{2}$ [20]. It reached $4-11 \mathrm{~kg} / \mathrm{m}^{3}$ in raceway RASs $[4,5,21,22]$ and $2-5 \mathrm{~kg} / \mathrm{m}^{3}$ in another experimental set up with a land-based closed RAS [19]. The increase in the final culture density in this study marks a breakthrough in RAS technology. Overall, the operating costs (excluding site fee and equipment depreciation) of the shrimp culture in this study amounted to about 22 $\mathrm{RMB} / \mathrm{kg}$. Considering that the average market price of Litopenaeus vannamei is $46 \mathrm{RMB} / \mathrm{kg}$, the profit per $\mathrm{kg}$ of shrimp would equal $24 \mathrm{RMB}$, and two sets of RAS could generate an income of 210,000 RMB for one shrimp crop. Therefore, the economic benefits of using this aquaculture technology are considerable.

Environmental parameters such as water temperature, salinity, dissolved oxygen (DO), and $\mathrm{pH}$ play an important role in the entire shrimp culture process, and changes in their values have important effects on the physiology of shrimp, in particular on growth, metabolism, reproduction, and molting $[23,24]$. The experiment was carried out between late May and late July in northern China. The external air temperature gradually increased during this time also determining a gradual increase in water temperature. The water temperature increased from 24.0 to $30.8^{\circ} \mathrm{C}$, within the suitable temperature range for the growth of Litopenaeus vannamei [25]. Studies have reported that the optimal salinity range for the growth of Litopenaeus vannamei is 15-25\% [23]. Due to limited freshwater resources available in the nursery farm, the salinity during the entire culture process varied between $25-32 \%$, and the shrimp still exhibited a relatively fast growth rate. With the increase in shrimp biomass and the proliferation of microorganisms in the biofilm, the oxygen consumption rate of both the shrimp and microorganisms increased, and the DO in the aquaculture water gradually decreased from the initial value of $7.0 \mathrm{mg} / \mathrm{L}$. The adding of liquid oxygen and the DO value above $5.0 \mathrm{mg} / \mathrm{L}$ ensures adequate shrimp growth and floc metabolism [26]. Under the highly intensive aquaculture conditions of the RAS, the $\mathrm{pH}$ value dropped rapidly due to the carbon dioxide produced through respiration and hydrogen ions produced by the nitrification of the biofilter [27]. After a month of RAS 
culture, the $\mathrm{pH}$ value dropped from 8.2 to about 7.0. By adding a small amount of calcium oxide $(\mathrm{CaO})$ or sodium bicarbonate to the system every day, the $\mathrm{pH}$ was maintained above 6.4. This necessary daily addition increases aquaculture costs, while maintaining a weakly acidic $\mathrm{pH}$ reduces the toxicity of ammonia nitrogen in the aquaculture water $[28,29]$ and does not add costs.

Pathogenic Vibrio is one of the main pathogens affecting Litopenaeus vannamei aquaculture, and estimates of the total number of Vibrio present in the culture can be used as an important indicator of the impact on the culture's health $[30,31]$. During the entire culture period, the total number of Vibrio bacteria in the system was maintained at 300-10,000 $\mathrm{cfu} / \mathrm{mL}$, and no diseases or abnormal mortality rates were reported. The number of bacteria increased gradually in later stages, but through the use of ultraviolet lamp sterilization and increased ozone input, it was successfully kept under control. The maximum abundance of Vibrio in aquaculture water was $10^{4} \mathrm{CFU} / \mathrm{mL}$, which was almost two logarithmic units lower than the $10^{6} \mathrm{CFU} / \mathrm{mL}$ pathogenicity level in water [31]. This pathogen concentration is comparable to that observed in previous research by Suantika et al. (2018) where the total number of Vibrio in a RAS culture of Litopenaeus vannamei was successfully controlled under low salinity conditions [9].

Ammonia nitrogen (especially free ammonia) and nitrite concentrations are also important factors that affect the health of Litopenaeus vannamei cultures [29,32]. In RASs, these concentrations are mainly reduced by biofilters [33]. In the initial period of recirculating aquaculture in this study, $10 \%$ of mature biomedia (sourced from a grouper RAS with a culture density of $80 \mathrm{~kg} / \mathrm{m}^{3}$ ) was added to promote the fast growth of biofilm in the new biomedia. During the first 20 days of culture, the TAN value remained within 2.0 $\mathrm{mg} / \mathrm{L}$. With the increase in feed amount, it exceeded $3.95 \mathrm{mg} / \mathrm{L}$ for four consecutive days by the 41 st day. At this time, the total feed amount in the two systems reached 226.8 $\mathrm{kg} / \mathrm{d}$, which represented the maximum feeding load of the system. Studies have reported that the "safe level" of TAN for rearing juvenile Litopenaeus vannamei is $3.95 \mathrm{mg} / \mathrm{L}$ [34]. Subsequently, $1 \mathrm{~m}^{3}$ of new biomedia was added to each system, and the daily feed amount was appropriately reduced to match the control of TAN in the systems. This was reduced to about $2 \mathrm{mg} / \mathrm{L}$ again through these measures. Studies recommended that the filling rate of the MBBR should not exceed 70\% [35,36]. In this study, it approached this critical value, giving full play to the water treatment capacity of the MBBR. With the increase in shrimp biomass, the demand for feed increased. The daily feed amount gradually increased to 270 $\mathrm{kg} / \mathrm{d}$ (on the 46 th day), and the TAN concentration on the 47 th day was $4.8 \mathrm{mg} / \mathrm{L}$, reaching again the maximum feeding load of the system. In later stages, TAN was controlled by appropriately reducing the feed amount until the end of the experiment. Ammonia tolerance in Litopenaeus vannamei increases with age [37], so the safe concentration of TAN tolerated by Litopenaeus vannamei should be greater than $3.95 \mathrm{mg} / 1$ in the later period of the culture. In this study, TAN was maintained below $3.95 \mathrm{mg} / \mathrm{L}$ as much as possible. Although TAN exceeded 3.95 for a few days in the late stage, the $\mathrm{pH}$ was lower than 7 , so the concentration of free ammonia was relatively low $[28,29]$. Therefore, there were no mortality events that could be attributed to high TAN values in the later stage of the culture.

Studies have reported that the "safe levels" of nitrite nitrogen for juvenile Litopenaeus vannamei placed at salinities of $25 \%$ and $35 \%$ were $15.2 \mathrm{mg} / \mathrm{L}$ and $25.7 \mathrm{mg} / \mathrm{L}$, respectively [38]. In the first 38 days of RAS culture, the concentration of nitrite nitrogen was within $1 \mathrm{mg} / \mathrm{L}$, and it gradually increased with the increase in feed amount, reaching a maximum of $4.5 \mathrm{mg} / \mathrm{L}$. By reducing the feed amount, nitrite nitrogen at the end of the culture process was finally reduced to approximately $2 \mathrm{mg} / \mathrm{L}$. The system salinity fluctuated between 25 and 32 during the entire period, so nitrite nitrogen concentrations in this experiment were safely far below the limit.

The procedures for Litopenaeus vannamei aquaculture in RASs are complex and highly controlled. In order to ensure effective water recirculation in the entire RAS, specific equipment including a device for the removal of shrimp shells, dead individuals, and sewage; microfilters; a foam fractionator; ultraviolet lamps; an ozone generator; and a 
liquid oxygen aerator were installed. Compared to open flow aquaculture technologies, the fluctuation of temperature, salinity, and $\mathrm{pH}$ during the whole recirculating aquaculture period was smaller [39]. Aeration facilities ensured the maintenance of the DO required for shrimp survival, and biofilters, UV lamps, and ozone effectively controlled the proliferation of pathogens. In particular, biofilters maintained TAN and nitrite nitrogen at safe levels.

\section{Conclusions}

With the support of key technologies for sewage collection, aeration, and variable flow installed in the rectangular aquaculture tanks, two sets of RASs for rearing Litopenaeus vannamei were constructed. Environmental factors required by Litopenaeus vannamei, such as water temperature, salinity, $\mathrm{DO}$, and $\mathrm{pH}$, were successfully controlled. Water quality indicators such as the total number of Vibrio bacteria, TAN, and nitrite were maintained within safe ranges. The yield of shrimp Litopenaeus vannamei reached $12.92 \mathrm{~kg} / \mathrm{m}^{3}$ after 92 days of culture. This study provides support of technology and industrial application for RAS of shrimp culture.

Supplementary Materials: The following are available online at https://zenodo.org/record/5136 341\#.YWQjWPmvywp, Figure S1: Panoramic view of the recirculating aquaculture system (A) and physical picture of equipment (B), Video S1: Shrimps (Litopenaeus vannamei) in the later stage of the recirculating aquaculture period.

Author Contributions: Y.D.-writing original draft and visualization. T.Q.-writing-review \& editing. L.Z., F.C., and J.X.-data curation. J.S.-writing-review \& editing and project administration. All authors have read and agreed to the published version of the manuscript.

Funding: This research was funded by the National Key R\&D Program of China (2019YFD0900502, 2017YFD0701703).

Institutional Review Board Statement: Not applicable.

Informed Consent Statement: Not applicable.

Data Availability Statement: The data presented in this study are available on request from the corresponding author. The data are not publicly available due to privacy or ethical restrictions.

Acknowledgments: The authors would like to give thanks to Dalian Yujia'ao Ecology Technology Co., Ltd., and Dalian Huixin Titanium Equipment Development Co., Ltd. for support during the experiment.

Conflicts of Interest: The authors declare no conflict of interest.

Ethical Approval: All applicable international, national, and institutional guidelines for the care and use of animals were followed. The procedures performed in studies involving animals were in accordance with the ethics committee at University of Chinese Academy of Science.

\section{References}

1. CSY. China Fishery Statistical Yearbook; China Agriculture Press: Beijing, China, 2019; pp. 1-22.

2. CSY. China Fishery Statistical Yearbook; China Agriculture Press: Beijing, China, 2020; pp. 1-24.

3. Cressey, D. Future Fish. Nature 2009, 458, 398-400. [CrossRef]

4. Reid, B.; Arnold, C.R. The intensive culture of the penaeid shrimp Penaeus vannamei Boone in a recirculating raceway system. J. World Aquac. Soc. 1992, 23, 146-153. [CrossRef]

5. Davis, D.A.; Arnold, C.R. The design, management and production of a recirculating raceway system for the production of marine shrimp. Aquac. Eng. 1998, 17, 193-211. [CrossRef]

6. Yang, J; Guan, C.; Song, H.; Liu, X.; Gu, Z.; Guo, Y. Design and test of mass balance-based recirculating aquaculture system for higher place shrimp pond. Trans. Chin. Soc. Agric. Eng. 2017, 33, 217-222, (In Chinese with English Abstract).

7. Liu, Y.; Yang, H.; Liu, S.; You, K.; Zhang, F. Experimental study on the approprite breeding density for the production of prawn in closed-recirculating system. Trans. Chin. Soc. Agric. Eng. 2005, 21, 122-125, (In Chinese with English Abstract).

8. Yang, J.; Ni, Q.; Zhang, Y.; Xu, B. Construction technology on RAS for shrimp culture. Trans. Chin. Soc. Agric. Eng. 2010, 26, 136-140, (In Chinese with English Abstract).

9. Suantika, G.; Situmorang, M.L.; Kurniawan, J.B.; Pratiwi, S.A.; Aditiawati, P.; Astuti, D.I.; Azizah, F.F.N.; Djohan, Y.A.; Zuhri, U.; Simatupang, T.M. Development of a zero water discharge (ZWD)-Recirculating aquaculture system (RAS) hybrid system for 
super intensive white shrimp (Litopenaeus vannamei) culture under low salinity conditions and its industrial trial in commercial shrimp urban farming in Gresik, East Java, Indonesia. Aquac. Eng. 2018, 82, 12-24.

10. Shi, Y.H.; Zhang, G.Y.; Liu, J.Z.; Zhu, Y.Z.; Xu, J.B. Performance of a constructed wetland in treating brackish wastewater from commercial recirculating and super-intensive shrimp growout systems. Bioresour. Technol. 2011, 102, 9416-9424. [CrossRef]

11. Guan, C.; Liu, H.; Zhang, Y. Experimental study on breeding Litopenaeu vannamei in recirculating aquaculture system. Fish. Modern. 2010, 38, 24-29, (In Chinese with English Abstract).

12. Fleckenstein, L.J.; Tierney, T.W.; Ray, A.J. Comparing biofloc, clear-water, and hybrid recirculating nursery systems (Part II): Tilapia (Oreochromis niloticus) production and water quality dynamics. Aquac. Eng. 2018, 82, 80-85. [CrossRef]

13. Fleckenstein, L.J.; Tierney, T.W.; Fisk, J.C.; Ray, A.J. Effects of supplemental LED lighting on water quality and Pacific white shrimp (Litopenaeus vannamei) performance in intensive recirculating systems. Aquaculture 2019, 504, 219-226. [CrossRef]

14. Chen, Z.; Chang, Z.Q.; Zhang, L.; Jiang, Y.L.; Ge, H.X.; Song, X.F.; Chen, S.B.; Zhao, F.Z.; Li, J. Effects of water recirculation rate on the microbial community and water quality in relation to the growth and survival of white shrimp (Litopenaeus vannamei). BMC Microbiol. 2019, 19, 192. [CrossRef]

15. Chen, F.; Xu, J.; Wei, Y.; Sun, J. Establishing an eyeball-weight relationship for Litopenaeus vannamei using machine vision technology. Aquac. Eng. 2019, 87. [CrossRef]

16. Du, Y.; Chen, F.; Zhou, L.; Qiu, T.; Sun, J. Effects of different layouts of fine-pore aeration tubes on sewage collection and aeration in rectangular water tanks. Aquac. Eng. 2020, 89, 102060. [CrossRef]

17. Chen, F.; Du, Y.; Qiu, T.; Xu, Z.; Zhou, L.; Xu, J.; Sun, M.; Li, Y.; Sun, J. Design of an intelligent variable-flow recirculating aquaculture system based on machine learning methods. Appl. Sci. 2021, 11, 6546. [CrossRef]

18. Ray, A.J.; Lotz, J.M. Shrimp (Litopenaeus vannamei) production and stable isotope dynamics in clear-water recirculating aquaculture systems versus biofloc systems. Aquac. Res. 2017, 48, 4390-4398. [CrossRef]

19. Baron-Sevilla, B.; Buckle-Ramirez, L.F.; Hernandez-Rodriguez, M. Intensive culture of Litopenaeus vannamei Boone 1931, in a recirculating seawater system. Cienc. Mar. 2004, 30, 179-188. [CrossRef]

20. Sandifer, P.A.; Hopkins, J.S.; Stokes, A.D. Intensive culture potential of Penaeus vannamei. J. World Aquac. Soc. 1987, 18, 94-100. [CrossRef]

21. Cohen, J.M.; Samocha, T.M.; Fox, J.M.; Gandy, R.L.; Lawrence, A.L. Characterization of water quality factors during intensive raceway production of juvenile Litopenaeus vannamei using limited discharge and biosecure management tools. Aquac. Eng. 2005, 32, 425-442. [CrossRef]

22. Mishra, J.K.; Samocha, T.M.; Patnaik, S.; Speed, M.; Gandy, R.L.; Ali, A.M. Performance of an intensive nursery system for the Pacific white shrimp, Litopenaeus vannamei, under limited discharge condition. Aquac. Eng. 2008, 38, 2-15. [CrossRef]

23. Zhang, P.; Zhang, X.; Li, J.; Huang, G. The effects of body weight, temperature, salinity, pH, light intensity and feeding condition on lethal DO levels of whiteleg shrimp, Litopenaeus vannamei (Boone, 1931). Aquaculture 2006, 256, 579-587. [CrossRef]

24. Moullac, G.L.; Haffner, P. Environmental factors affecting immune responses in Crustacea. Aquaculture 2000, 191, 121-131. [CrossRef]

25. Ponce-Palafox, J.; Martinez-Palacios, C.A.; Ross, L.G. The effects of salinity and temperature on the growth and survival rates of juvenile white shrimp, Penaeus vannamei, Boone, 1931. Aquaculture 1997, 157, 107-115. [CrossRef]

26. Seidman, E.R.; Lawrence, A.L. Growth, feeding digestibility, and proximate body composition of juvenile Penaeus vannamei and Penaeus monodon grown at different dissolved oxygen levels. J. World Maric. Soc. 1985, 16, 333-346. [CrossRef]

27. Lin, Y.F.; Jing, S.R.; Lee, D.Y.; Chang, Y.F.; Chen, Y.M.; Shih, K.C. Performance of a constructed wetland treating intensive shrimp aquaculture wastewater under high hydraulic loading rate. Environ. Pollut. 2005, 134, 411-421. [CrossRef] [PubMed]

28. Bower, C.E.; Bidwell, J.P. Ionization of ammonia in seawater: Effects of temperature, $\mathrm{pH}$ and salinity. J. Fish. Res. Board Can. 1978, 35, 1012-1016. [CrossRef]

29. Barajas, F.M.; Villegas, R.S.; Clark, G.P.; Mosqueda, J.G.; Moreno, B.L. Daily variation in short-term static toxicity of unionized ammonia in Litopenaeus vannamei (Boone) postlarvae. Aquac. Res. 2006, 37, 1406-1412. [CrossRef]

30. Bauer, J.; Teitge, F.; Neffe, L.; Adamek, M.; Jung, A.; Peppler, C.; Steinhagen, D.; Jung-Schroers, V. Recommendations for identifying pathogenic Vibrio spp. as part of disease surveillance programmes in recirculating aquaculture systems for Pacific white shrimps (Litopenaeus vannamei). J. Fish Dis. 2018, 41, 1877-1897. [CrossRef]

31. Pena, L.D.D.L.; Lavilla-Pitogo, C.R.; Paner, M.G. Luminescent vibrios associated with mortality in pond-cultured shrimp Penaeus monodon in the Philippines: Species Composition. Fish Pathol. 2001, 36, 133-138. [CrossRef]

32. Hargreaves, J.A. Nitrogen biogeochemistry of aquaculture ponds. Aquaculture 1998, 166, 181-212. [CrossRef]

33. Timmons, M.B.; Ebeling, J.M. Recirculating Aquaculture, 2nd ed.; Cayuga Aqua Ventures: Ithaca, NY, USA, 2007 ; pp. $275-314$.

34. Lin, Y.C.; Chen, J.C. Acute toxicity of ammonia on Litopenaeus vannamei Boone juveniles at different salinity levels. J. Exp. Mar. Biol. Ecol. 2001, 259, 109-119. [CrossRef]

35. Rusten, B.; Eikebrokk, B.; Ulgenes, Y.; Lygren, E. Design and operations of the Kaldnes moving bed biofilm reactors. Aquac. Eng. 2006, 34, 322-331. [CrossRef]

36. Pfeiffer, T.J.; Wills, P.S. Evaluation of three types of structured floating plastic media in moving bed biofilters for total ammonia nitrogen removal in a low salinity hatchery recirculating aquaculture system. Aquac. Eng. 2011, 45, 51-59. [CrossRef] 
37. Frias-Espericueta, M.G.; Harfush-Melendez, M.; Páez-Osuna, F. Effects of ammonia on mortality and feeding of postlarvae shrimp Litopenaeus vannamei. Bull. Environ. Contam. Toxicol. 2000, 65, 98-103. [CrossRef] [PubMed]

38. Lin, Y.C.; Chen, J.C. Acute toxicity of nitrite on Litopenaeus vannamei (Boone) juveniles at different salinity levels. Aquaculture 2003, 224, 193-201. [CrossRef]

39. Menasueta, P.; Aranyakanonda, P.; Rungsupa, S.; Moree, N. Maturation and larviculture of Penaeid prawns in closed recirculating seawater systems. Aquac. Eng. 1989, 8, 357-368. [CrossRef] 